\title{
ANÁLISE DA GESTÃO DA MANUTENÇÃO EMPREGADA EM SISTEMAS REDUNDANTES
}

\section{ANALYSIS OF MAINTENANCE MANAGEMENT APPLIED IN REDUNDANT SYSTEMS}

\author{
Angélica Alebrant Mendes ${ }^{1}$; José Luís Duarte Ribeiro ${ }^{2}$ \\ ${ }^{1}$ Universidade Federal do Rio Grande do Sul - UFRGS \\ angelalebrant@yahoo.com.br \\ ${ }^{2}$ Universidade Federal do Rio Grande do Sul - UFRGS \\ ribeiro@producao.ufrgs.br
}

\begin{abstract}
Resumo
Este artigo tem por objetivo identificar os métodos de análise de confiabilidade e segurança $e$ gestão da manutenção atualmente empregados nas empresas que utilizam sistemas redundantes. $A$ pesquisa, de caráter qualitativo, baseou-se em informações obtidas na literatura, juntamente com informações levantadas durante a realização de entrevistas individuais semiestruturadas com os responsáveis pela manutenção de três empresas de grande porte: uma refinaria de petróleo, uma empresa siderúrgica e uma empresa produtora de alimentos a base de soja. Após a análise das eventuais deficiências e beneficios dos métodos de análise de confiabilidade/segurança e gestão da manutenção empregados pelas empresas em cada tipo de sistema redundante, foi elaborado, como resultado, um quadro comparativo de tipos de redundâncias, métodos de análise de confiabilidade/segurança e gestão da manutenção utilizados e métodos de análise de confiabilidade/segurança e gestão da manutenção recomendados. Observou-se que, ainda que as empresas possuam sistemas aparentemente confiáveis, não são utilizados métodos quantitativos para a definição de intervalos de manutenção, nem são feitos cálculos para estimar a confiabilidade dos sistemas. Apesar de coletarem dados de falhas e de manutenções ocorridas, as empresas não dispõem de métodos efetivos para determinar quantitativamente a sua confiabilidade.
\end{abstract}

Palavras-chave: manutenção centrada em confiabilidade; sistemas redundantes; planejamento da manutenção.

\section{Introdução}

\subsection{Cenário atual e inserção do tema mais amplo neste cenário}

A competitividade entre as empresas tem conduzido as organizações a buscarem novas estratégias de mercado e reduzirem seus custos operacionais. A melhoria das atividades de manutenção e sua visualização como uma função estratégica para aumentar a produtividade pode, não somente, reduzir estes custos e propiciar o aumento do faturamento, como também proporcionar melhorias na segurança, nas relações com o meio ambiente e no atendimento aos requisitos normativos da empresa. Logo, melhorias na confiabilidade e disponibilidade dos equipamentos 
produtivos podem contribuir significativamente para aumentar a competitividade das organizações (SANTOS et al, 2007; MÁRQUEZ et al, 2009; PINTO, XAVIER, 2001; BLOOM, 2006; RAUSAND, 1998).

Neste contexto, muitas empresas ao redor do mundo já perceberam a importância de uma gestão da manutenção efetiva, principalmente no que se refere aos recursos por ela demandados e a sua influência direta na disponibilidade produtiva (NGUYEN et al, 2008). A eficácia dos custos empregados e a acurácia das atividades são os dois critérios básicos para uma boa manutenção. A redução dos custos de manutenção possibilita o aumento dos lucros da empresa e a acurácia das atividades garante uma operação contínua e confiável dos equipamentos (NIU et al, 2010).

\subsection{Inserção do tema específico no tema mais amplo}

Dois conceitos importantes surgidos com a Manutenção Centrada em Confiabilidade são as falhas escondidas e as falhas múltiplas. Falhas escondidas ocorrem quando a perda da função do equipamento não é evidente para o pessoal operacional. Esse tipo de falha ocorre normalmente em componentes com redundância, onde as consequências da falha não são aparentes instantaneamente, sendo dependentes de uma segunda falha em outro componente. Componentes redundantes com falhas escondidas muitas vezes são classificados erroneamente como itens que podem rodar-até-afalha. $\mathrm{O}$ grande problema deste tipo de classificação é a falsa sensação de proteção do sistema, pois, de fato, uma falha catastrófica pode ocorrer a qualquer momento após uma segunda falha. O ideal, neste caso, seria uma análise de falhas múltiplas, com a determinação de uma atividade de manutenção periódica de procura por falhas (BLOOM, 2006). A compreensão do conceito de redundância e suas formas de operação no sistema são fundamentais para uma correta análise de confiabilidade da planta (BLOOM, 2006; LAFRAIA, 2001).

Desta forma, o tema desta pesquisa é Manutenção e Confiabilidade. Como tema específico tem-se a manutenção de sistemas redundantes, a fim de analisar os diferentes tipos de sistemas redundantes existentes e os métodos de manutenção desses sistemas utilizados pelas empresas.

\subsection{Problema de pesquisa}

O problema de pesquisa deste trabalho é a necessidade de identificação dos tipos e características de sistemas redundantes utilizados pelas empresas e dos métodos empregados para a manutenção desses sistemas.

\subsection{Revisão de literatura}

Segundo Fogliatto e Ribeiro (2009) sistema redundante significa que há mais de um componente disponível para realizar uma determinada função. Componentes redundantes normalmente são empregados para aumentar a confiabilidade do sistema, contudo, se a detecção e 
restauração da falha deste componente não forem imediatas, o sistema passa a operar desprotegido. Para os autores, existem basicamente três tipos de redundância. A redundância pura ocorre quando todos os componentes são ativados quando o sistema é ativado, e eventuais falhas não afetam a confiabilidade dos componentes sobreviventes. Na redundância com carga compartilhada, a taxa de falha dos componentes sobreviventes aumenta à medida que falhas ocorrem, como, por exemplo, em turbinas de aviões. Na redundância em standby ou back up, por sua vez, o componente redundante somente é ativado se um dos componentes em operação falhar.

Sistemas que requerem altos níveis de confiabilidade, como, por exemplo, controles de aeronaves e naves espaciais, frequentemente utilizam redundâncias para assegurar o desempenho desejado (MYERS e RAUZY, 2008).

Na Figura 1 são apresentados alguns tipos de redundâncias conforme descrito por Bloom (2006). No primeiro cenário as duas válvulas são normalmente operantes, ainda que apenas uma válvula seja suficiente para executar a função. Ambas as válvulas possuem sistema indicador de operação individual, o que permite a identificação imediata da falha de qualquer uma das duas válvulas. Um exemplo típico deste tipo de redundância são as turbinas de um avião.

No segundo cenário as duas válvulas são normalmente operantes, ainda que apenas uma válvula seja suficiente para executar a função. O sistema indicador de operação é compartilhado por ambas as válvulas, o que não permite a identificação imediata da falha, pois a função é totalmente cumprida pela válvula que não falhou.

No terceiro cenário uma das válvulas é normalmente operante e a outra é normalmente inoperante, ou seja, só funciona quando a primeira válvula falha. Este tipo de sistema também é conhecido como standby ou back up. Neste cenário, a falha da válvula normalmente operante é detectada por um sistema indicador de operação e este sistema envia, imediatamente, um sinal para a válvula back up começar a operar.

O quarto cenário é idêntico ao terceiro, porém o back up é ativado manualmente assim que a perda da função do sistema e a falha da válvula normalmente operante são identificadas.

Nos cenários três e quatro há a necessidade de inspeções periódicas nos back ups, caso contrário, ao ser acionado, o back up pode não funcionar como o esperado e uma falha total do sistema pode ocorrer. O cenário quatro somente deve ser empregado quando a falha do sistema for admissível, pois o back up será ativado manualmente após a falha. 
Figura 1 - Cenários com válvulas redundantes

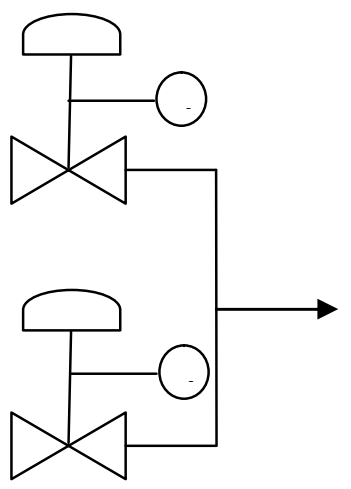

1. Válvulas Redundantes com falha evidente Ambas as válvulas funcionam simultaneamente

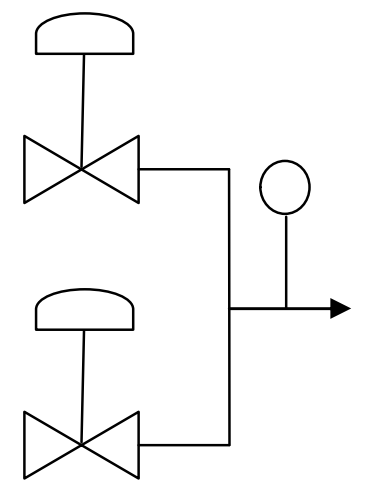

2. Válvulas Redundantes com falha escondida Ambas as válvulas funcionam simultaneamente

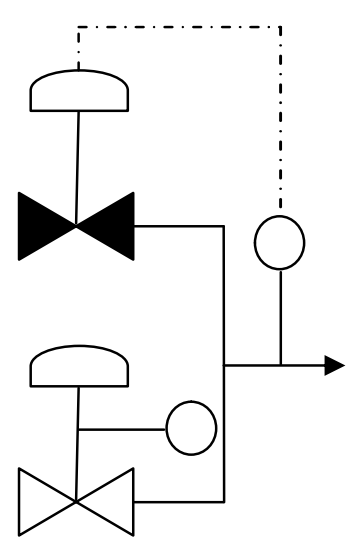

3. Válvulas Redundantes com falha escondida Válvula normalmente fechada, com abertura automática ao sinal de falha da válvula normalmente operante

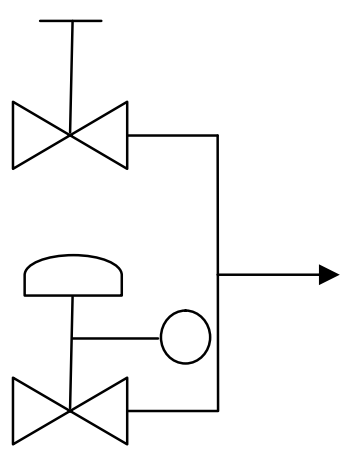

4. Válvulas Redundantes com falha escondida Válvula normalmente fechada, com abertura manual ao sinal de falha da válvula normalmente operante

Fonte: Adaptado de BLOOM (2006)

No cenário dois, há a necessidade de inspeções periódicas em ambas as válvulas, pois a falha de uma única válvula não é evidente e a falha da segunda válvula gera a interrupção do funcionamento do sistema.

Alguns trabalhos na literatura analisam e modelam a confiabilidade de sistemas redundantes. Entre eles esta o trabalho de (MYERS, RAUZY, 2008) que descreve duas importantes classes de coberturas de falhas imperfeitas para modelar a confiabilidade de sistemas redundantes. O trabalho descreve, fundamentalmente, dois tipos de estruturas de gerenciamento de redundâncias: uma baseada no uso de diagnósticos automáticos associados a cada um dos elementos redundantes e outra baseada no uso de sistemas $k$-em- $n$ com múltiplos modos de falha.

Marseguerra et al (2005) afirmam que, na prática, simplesmente maximizar a estimativa de confiabilidade dos sistemas não é suficiente, pois os tomadores de decisão necessitam avaliar 
também a incerteza existente nesta estimativa, a fim de escolher opções de menor risco. Para tanto, os autores sugerem o uso de algoritmos genéticos com múltiplos objetivos na seleção de um design que proporcione alta confiabilidade e que apresente baixa incerteza de estimação.

Hsieh (2002) apresenta um modelo que utiliza programação linear para solucionar problemas de sistemas série-paralelo redundantes sujeitos a múltiplas restrições, onde cada subsistema possui múltiplas opções de componentes. O estudo enfatiza que, ainda que não existam garantias de que a proposta apresentada resulte em um ótimo global, resultados numéricos limitados demonstraram sua eficiência.

Em um estudo semelhante, Azaron et al (2009) apresenta um modelo para a otimização da confiabilidade de sistemas redundantes multicomponentes em standby, com $k$ elementos não reparáveis diferentes, baseado em algoritmos genéticos e utilizando também Processos de Markov e Programação por objetivos. Sendo que o objetivo principal do problema de otimização da confiabilidade é selecionar os melhores componentes disponíveis para serem alocados em stand by no sistema.

Elerath e Pecht (2009) apresentam um método para modelar sistemas reparáveis, utilizando Simulação de Monte Carlo, que elimina a suposição de que os componentes e os sistemas necessitam ser modelados utilizando-se processos de Poisson homogêneos.

Dhillon e Subramanian (2001) apresentam cinco novos modelos desenvolvidos para sistemas 2-em-3 componentes (redundância tripla). Neste trabalho são apresentadas expressões para confiabilidade e tempo médio até a falha para sistemas com componentes sujeitos e não sujeitos a reparos baseadas no método das Cadeias de Markov.

Zhang e Wang (2007) aplicam o modelo de reparo de processos geométricos em um sistema redundante de dois componentes onde um deles é totalmente reparável, ou seja, suas condições de funcionamento após o reparo são idênticas às iniciais, e o outro componente segue um processo geométrico de envelhecimento e possui prioridade de uso. Como resultado principal, o trabalho determina a política ótima de substituição baseada no tempo de operação do componente principal.

Courtois e Delsarte (2006) propõem em seu artigo a definição de um intervalo ótimo entre inspeções periódicas para componentes redundantes. Buscando solucionar o conflito entre perda de confiabilidade durante as inspeções de redundâncias e os benefícios em confiabilidade proporcionados por inspeções mais frequentes, os autores apresentam uma expressão para o intervalo ótimo para um caso geral de sistema redundante obtida através de transformações e identificações de variáveis.

Questionando a real vantagem do uso de redundâncias, Paté-Cornell et al (2004) afirmam que há a necessidade de quantificação dos riscos do uso ou não de redundâncias. Os autores lembram que as vantagens em termos de confiabilidade de componentes ou sistemas redundantes só 
são válidas quando suas falhas são independentes, fato que raramente acontece. Por exemplo, os componentes redundantes normalmente estão sujeitos as mesmas condições externas e, no caso de componentes idênticos, aos mesmos erros de design. $\mathrm{O}$ uso de redundâncias não idênticas pode evitar erros de design comuns, contudo, o emprego de redundâncias não idênticas é muito mais oneroso devido aos custos duplos de desenvolvimento.

\subsection{Objetivos e justificativa de trabalho}

Este trabalho possui como objetivo identificar os métodos de análise de confiabilidade e segurança e gestão da manutenção, atualmente empregados nas empresas que utilizam sistemas redundantes.

Se um sistema não é considerado suficientemente robusto para exercer a função desejada, duas técnicas podem ser utilizadas para melhorar sua confiabilidade: a primeira é o uso de componentes altamente confiáveis na estruturação do sistema, a segunda é a adição de componentes redundantes em vários subsistemas do sistema. Visto que, normalmente, a aquisição de componentes altamente confiáveis demanda um investimento superior à adição de componentes redundantes, a utilização de redundâncias é largamente empregada em sistemas que possuem impacto na segurança da operação dos equipamentos ou da planta.

Contudo, a confiabilidade de sistemas críticos em termos de segurança depende tanto da sua configuração e projeto, quanto da gestão de sua operação e manutenção. Em sistemas redundantes com inspeção periódica, se um componente redundante falhar durante o intervalo entre manutenções o sistema fica desprotegido até a próxima inspeção, correndo risco de ocorrer uma falha catastrófica a qualquer momento se o segundo componente redundante falhar.

Do mesmo modo, sistemas redundantes com monitoração contínua, estão sujeitos a falhas que podem envolver tempo de diagnóstico e reparo significativo. Durante este tempo, o sistema perde a redundância e fica desprotegido, podendo ocorrer uma falha catastrófica a qualquer momento se o segundo componente redundante falhar.

Além disso, outro problema que pode ocorrer é a presença de causas de falha comuns. Nesse caso, a mesma causa provoca a falha de todos os componentes redundantes, virtualmente eliminando a segurança usualmente presente em sistemas redundantes.

A justificativa acadêmica para o tema está relacionada ao fato de que, apesar de existirem métodos que solucionam tais problemas, supõe-se que as empresas que utilizam redundâncias não os empregam corretamente. Assim, o levantamento dos métodos utilizados, de suas eventuais deficiências e benefícios constituem a etapa inicial para a melhoria da gestão da manutenção desses sistemas. 


\subsection{Estrutura do trabalho}

Este artigo está estruturado em quatro seções. Na Seção 2 é apresentada a metodologia utilizada para realizar o trabalho e solucionar o problema de pesquisa. Na Seção 3 é apresentado detalhadamente o estudo aplicado, os resultados obtidos, bem como sua discussão. Por fim, na Seção 4, são apresentadas as conclusões referentes ao estudo realizado.

\section{Metodologia}

\subsection{Cenário}

A pesquisa foi realizada em três empresas. Uma refinaria de petróleo, uma empresa produtora de alimentos a base de soja e uma siderúrgica. Todas as empresas são de grande porte, líderes em seus segmentos e localizadas na região metropolitana de Porto Alegre.

\subsection{Etapas de pesquisa}

A pesquisa é composta pelas seguintes etapas: i) Revisão de literatura sobre Manutenção, Confiabilidade e Sistemas; ii) Realização de entrevistas individuais semiestruturadas com os responsáveis pela manutenção das empresas selecionadas, buscando a identificação dos sistemas redundantes em operação e dos métodos de análise de confiabilidade/segurança e gestão da manutenção empregados; iii) Transcrição e organização dos dados coletados quanto à tipos de redundância e métodos de análise de confiabilidade/segurança e gestão da manutenção; iv) Análise das eventuais deficiências e benefícios dos métodos de análise de confiabilidade/segurança e gestão da manutenção empregados pelas empresas em cada tipo de sistema redundante; v) Elaboração de um quadro comparativo de tipos de redundâncias, métodos de análise de confiabilidade/segurança e gestão da manutenção utilizados e métodos de análise de confiabilidade/segurança e gestão da manutenção recomendados.

\subsection{Coleta de dados}

Os dados foram coletados nas três empresas identificadas anteriormente. Cada empresa possui alguns sistemas redundantes empregados. A coleta de dados não se deteve ao número geral de sistemas redundantes existentes em cada empresa, e sim aos tipos de sistemas redundantes utilizados.

A escolha prévia das empresas a serem estudadas foi baseada na facilidade de acesso aos entrevistados, de forma a agilizar as tarefas de coleta de dados e estudo dos sistemas redundantes. As entrevistas foram realizadas com base em um roteiro de questões semiestruturadas. O Roteiro de Questões utilizado é apresentado na sequência: 
1. Explicação dos objetivos do trabalho e confirmação da disponibilidade para participação;

2. Quais os sistemas redundantes existentes na empresa? Como funcionam? Quais os riscos de falha?

3. Como é feita a manutenção desses sistemas? Periodicidade, método;

4. Em quais situações ambos os componentes do sistema redundante poderiam falhar (por baixa frequência de inspeção, durante o reparo, causas comuns)?

5. Já ocorreu alguma situação dessas?

6. Pergunta resumo, resumindo as informações coletadas e verificando a precisão dos registros;

7. Pergunta final e agradecimento.

\subsection{Registro dos dados}

Os dados foram registrados manualmente no formulário de Roteiro de questões. Os dados de cada tipo de redundância foram registrados em Roteiros de questões individuais. Não foi utilizado gravador para não inibir os entrevistados, visto que se trata de um tema relacionado à segurança da fábrica.

\subsection{Tratamento dos dados}

Os dados foram classificados em tipos de redundância e métodos de análise de confiabilidade/segurança e gestão da manutenção. Algumas características individuais de cada empresa também foram destacadas, a fim de diferenciar as empresas em termos de níveis de confiabilidade e entender os motivos do maior ou menor número de sistemas redundantes empregados.

\subsection{Análise dos dados}

Foi elaborado um quadro comparativo de tipos de redundâncias, métodos de análise de confiabilidade/segurança e gestão da manutenção utilizados e métodos de análise de confiabilidade/segurança e gestão da manutenção recomendados. Para cada método, foram identificadas as deficiências nos procedimentos adotados e os benefícios dos procedimentos recomendados.

Através dos resultados, foi possível visualizar se as empresas conhecem e empregam métodos adequados para a análise de confiabilidade/segurança e gestão da manutenção. Se não empregam, o porquê da não utilização. Além disso, foi possível identificar os riscos de segurança e confiabilidade decorrentes da utilização de métodos inapropriados. 


\section{Estudo aplicado}

A seguir é apresentado o estudo aplicado deste artigo. Inicialmente é feita a descrição dos dados coletados nas entrevistas, seguido de sua análise e interpretação.

\subsection{Descrição}

A entrevista com o gestor da manutenção da refinaria de petróleo demonstrou que a empresa emprega intensamente sistemas redundantes na planta industrial. A grande maioria dos equipamentos utilizados, principalmente bombas, possui um equipamento semelhante instalado em paralelo, de forma a garantir o funcionamento contínuo da linha produtiva. Equipamentos maiores e mais complexos, como alguns compressores, devido ao elevado custo de aquisição, não possuem sistema redundante operando em paralelo. Contudo, durante a aquisição desses equipamentos são avaliadas questões referentes à sua qualidade e confiabilidade, de forma a garantir a aquisição de equipamentos robustos e que possuam monitoramento contínuo de falhas integrado.

O tipo de redundância empregada é a standby ou back up, onde um equipamento é normalmente operante e o outro é normalmente inoperante, funcionando como reserva em caso de falha do equipamento principal. A ativação do equipamento redundante normalmente é feita de forma automática, devido aos riscos de segurança e custos envolvidos na falha de operação da planta. Porém, para os casos onde a falha pode ser tolerada por um determinado período de tempo, são empregados sistemas de ativação manual do back up. Não são empregados sistemas redundantes com carga compartilhada.

Os equipamentos redundantes funcionam em regime de rodízio chamado 3 por 1 . Ou seja, os equipamentos mais novos funcionam três semanas consecutivas, parando uma semana para o funcionamento do equipamento reserva e voltando a operar na semana seguinte. Para o gestor, este regime de rodízio evita falhas simultâneas dos equipamentos, visto que cada equipamento está em uma fase diferente do seu ciclo de vida. Os equipamentos em fase de desgaste saem do regime de rodízio e passam a operar apenas em situações emergenciais, onde o sistema redundante falhe.

A manutenção preditiva, como, por exemplo, a análise de vibrações, é largamente utilizada na refinaria de petróleo. Somente se aplica manutenção preventiva baseada no tempo naqueles equipamentos ou componentes que apresentam falhas não detectáveis por técnicas de manutenção preditiva. Outra opção empregada é a utilização de alguma técnica de manutenção preditiva que não seja totalmente eficaz para a detecção das falhas, mas que permita o espaçamento das intervenções preventivas baseadas no tempo.

Os intervalos entre as manutenções preditivas e preventivas são determinados com base nos manuais do fabricante e na experiência da equipe de manutenção, sendo que estes intervalos devem, preferivelmente, serem compatíveis com o regime de rodízio empregado, de forma a aproveitar o 
tempo em que os equipamentos estão inoperantes. $\grave{A}$ medida que as manutenções preditivas detectam o início do processo de falha do equipamento, o intervalo entre manutenções é reduzido, intensificando-se as inspeções, a fim de evitar que o equipamento falhe entre o período de intervenções. Da mesma forma, equipamentos em que, após determinado tempo, se verifica a possibilidade de aumento do intervalo entre intervenções devido a suas boas condições de operação, o intervalo é ampliado.

Quanto a situações onde ambos os equipamentos do sistema redundante podem falhar, destacaram-se as causas comuns de degradação do produto e defeito de fabricação. A degradação do produto ocorre devido a um descontrole operacional que causa a não conformidade do produto. Este produto não conforme gera falha do equipamento em operação do sistema redundante e, automaticamente, gera a falha do equipamento reserva assim que este começa a operar. Este tipo de incidente já foi relatado na empresa. $\mathrm{O}$ defeito de fabricação ocorre em equipamentos novos no momento da partida, onde ambos os equipamentos possuem o mesmo defeito e falham simultaneamente. Visando reduzir os danos causados por defeito de fabricação e falhas prematuras, a empresa emprega uma rígida avaliação e inspeção do equipamento novo em início de operação.

A entrevista com o gestor da manutenção da empresa siderúrgica demonstrou que a empresa utiliza poucos sistemas redundantes em sua planta fabril. Redundâncias são usadas basicamente no setor de utilidades (redes de ar comprimido, água e energia elétrica), no sistema de água para o resfriamento de fornos e nas caldeiras.

No setor de utilidades, assim como nas caldeiras, o tipo de redundância empregada é a standby ou back up, onde um equipamento é normalmente operante e o outro é normalmente inoperante, funcionando como reserva em caso de falha do equipamento principal. A ativação do equipamento redundante normalmente é feita de forma automática, devido aos riscos de segurança e custos envolvidos na falha de operação da planta. Porém, para os casos onde a falha pode ser tolerada por um determinado período de tempo, são empregados sistemas de ativação manual do back up. Um sistema semelhante a um sistema redundante com carga compartilhada é empregado no sistema de água para resfriamento dos fornos. O sistema é composto por três fornos e três reservatórios de água para resfriamento. A princípio, cada reservatório de água atende apenas um forno, contudo, em caso de falha em no bombeamento de água de algum reservatório para algum forno, um mesmo reservatório pode fornecer água para mais de um forno.

O abastecimento desses reservatórios de água é feito através de uma bomba elétrica que bombeia a água da rede da concessionária para os reservatórios. Caso essa bomba elétrica falhe por falta de energia, uma bomba a diesel é ativada, funcionando como back up da bomba elétrica. Além disso, há um terceiro back up: se a bomba a diesel também falhar, há um reservatório de água extra, cheio, que somente é ativado em casos de emergência. A falha da bomba elétrica seria uma causa 
comum para falha do sistema de resfriamento de fornos, onde todos os reservatórios perderiam o abastecimento de água e, consequentemente, gerariam um superaquecimento dos fornos. Contudo, como ação de contingência para esta falha, há os back ups constituídos pela bomba a diesel e pelo reservatório extra.

Nos equipamentos dos sistemas redundantes, tanto o ativo, como o reserva, é empregada principalmente a manutenção preventiva baseada no tempo, sendo controlada pelas horas de operação de cada equipamento. Podem ser empregadas, também, manutenções preditivas como, por exemplo, técnicas de análise de óleo e termografia.

Os intervalos entre manutenções preventivas e preditivas são determinados com base nos manuais do fabricante e na experiência da equipe de manutenção. Um equipamento pode ter seu intervalo de manutenção preditiva aumentado ou diminuído, conforme o estado do seu processo de falha.

A entrevista com o gestor da manutenção da empresa produtora de alimentos a base de soja revelou a baixa utilização de sistemas redundantes, visto que o gestor prefere empregar o controle e a prevenção para prevenir a ocorrência de falhas, ao invés de fazer investimentos elevados em redundâncias. Foram citados dois sistemas redundantes, um existente nas caldeiras e outro na linha de fornecimento de água contra incêndio.

A linha de fornecimento de água contra incêndio possui três bombas em paralelo, funcionando como sistema de back ups, sendo que apenas uma é suficiente para suprir o fornecimento de água. Das três bombas, duas são ativadas por energia elétrica e uma usa gasolina como combustível. Além disso, há um gerador de energia elétrica que pode entrar em operação caso ocorra falha no abastecimento pela concessionária. Desta forma, o gerador e a bomba a combustível evitam falha no sistema causada pela falha no suprimento de energia elétrica, que se configura como uma causa comum.

A caldeira possui uma caldeira reserva, do tipo back up, que é inspecionada temporariamente através de um check-list. O intervalo de tempo em que a caldeira reserva é colocada em funcionamento é baseado nas recomendações do fabricante e na experiência da equipe de manutenção.

Outras causas comuns que ocasionariam a interrupção do processo, citadas pelo gestor, foram a falta de água para o processo e a falta de alimentação de soja, visto que a empresa possui um processo contínuo de produção, porém, nenhuma dessas causas foi relatada.

\subsection{Análise}

As entrevistas revelaram que a intensidade do uso de redundâncias depende do tipo de processo da empresa e dos riscos, em termos de segurança, envolvidos na ocorrência da falha. A empresa refinaria de petróleo emprega intensamente sistemas redundantes em seu processo. Este 
fato se deve ao maior risco de segurança e ambiental envolvido na falha de algum equipamento do processo e ao tipo de processo e produto existente na planta, onde os equipamentos são relativamente simples e de custo mais acessível. Além disso, por se tratar de uma empresa pública, observa-se a maior disponibilidade de recursos para compra de equipamentos redundantes. A empresa siderúrgica, por sua vez, emprega um número menor de redundâncias devido ao menor risco de seu processo e ao tipo de equipamento utilizado, normalmente de grande porte e elevado custo de aquisição e operação. A empresa de alimentos a base de soja emprega pouquíssimos sistemas redundantes devido ao baixo risco de segurança e ambiental envolvido na ocorrência de falha e ao tipo de equipamento utilizado, normalmente de grande porte e alto custo de aquisição e operação. Além disso, a empresa confia muito na eficácia de sua manutenção preventiva.

A empresa siderúrgica e a empresa de alimentos a base de soja somente utilizam redundâncias no setor de utilidade (água, ar comprido), onde a falha gera alto risco de segurança e há um elevado custo operacional relacionado à interrupção do abastecimento, ao mesmo tempo em que os custos para a aquisição do equipamento redundante são baixos. Ambas as empresas também citaram a utilização de redundância no sistema de caldeiras devido ao tempo excessivo gasto para resfriamento (parada) e aquecimento (início da operação), tempo que, em casos de falha ou necessidade de manutenção preventiva, seria impraticável.

Em locais onde há um grande risco de segurança relacionado à falha, como no resfriamento dos fornos da siderúrgica e na linha de água contra incêndio da empresa de alimentos a base de soja, utilizam-se redundâncias inativas diferentes em vários níveis. O fato da redundância ser diferente, por exemplo: bomba elétrica e bomba à diesel, garante o funcionamento do sistema em casos de ocorrência de falhas por causas comuns já previstas no sistema.

Nenhuma das empresas entrevistadas utiliza sistemas redundantes normalmente ativos com carga compartilhada. Os gestores da manutenção acreditam não ser um modelo eficaz devido à possibilidade de falha simultânea gerada pelo fato de que ambos estariam na mesma etapa do ciclo de vida. Soma-se a isso a impossibilidade de realizar a manutenção no equipamento inativo.

O sistema de rodízio de três semanas para uma, utilizado pela refinaria de petróleo, reduz a probabilidade de falhas simultâneas ao mesmo tempo em que mantém os equipamentos em funcionamento, evitando falhas relacionadas à partida ou à sua baixa utilização. Além disso, a estratégia de realizar as manutenções em intervalos coincidentes com o rodízio facilita a efetiva execução da manutenção, pois elimina a necessidade de parar o equipamento somente para a execução da manutenção.

A possibilidade de retirada do sistema de rodízio dos equipamentos em fase de desgaste garante a segurança e confiabilidade, sem a necessidade de aumentar a frequência de manutenções 
preventivas e corretivas. Contudo, implica em um custo adicional de aquisição de novos equipamentos, podendo ser proibitivo para empresas que dispõem de poucos recursos.

Para a empresa siderúrgica e a empresa de alimentos a base de soja, o uso de rodízios pode ser uma prática pouco adequada, devido ao tipo e equipamento utilizado no processo e ao tipo de redundância empregada. Equipamentos grandes, que exigem um alto investimento e possuem alto custo de operação, principalmente na partida, e sistemas redundantes com equipamentos diferentes são pouco apropriados para o sistema de rodízio.

O emprego de técnicas de manutenção preditiva reduz os custos relacionados à troca antecipada de componentes e possibilita um aumento da confiabilidade através do acompanhamento da condição real do equipamento. Porém, o uso deste tipo de manutenção requer a utilização de equipamentos especiais e a contratação de mão-de-obra especializada, o que, normalmente, torna esse tipo de manutenção mais cara que a preventiva baseada no tempo. Assim, seu uso somente é justificável em empresas que possuem um grande número de equipamentos semelhantes onde possa ser empregada a mesma técnica. Isso explica a utilização intensa de manutenção preditiva na refinaria de petróleo e a utilização moderada nas demais empresas.

Quanto às causas comuns de falha de ambos os equipamentos do sistema redundante, as três empresas relataram suas possibilidades. Em casos mais graves, as falhas são evitadas utilizando sistemas redundantes com equipamentos diferentes, em outros, julga-se que a falha seja pouco provável ou não gere um dano catastrófico.

\subsection{Interpretação}

Observa-se que as empresas entrevistadas utilizam sistemas redundantes conforme sua necessidade em termos de segurança. Em locais onde existe um elevado risco relacionado à segurança, são empregados sistemas redundantes a fim de garantir segurança e confiabilidade. $\mathrm{O}$ grau de utilização varia conforme o tipo de processo envolvido, ou seja, processos em que os equipamentos utilizados são mais simples possuem um maior número de redundâncias empregadas.

Como tipo de sistema redundante é utilizado o tipo back up, onde um segundo equipamento com a mesma função é mantido em paralelo, pronto para entrar em operação, caso o primeiro equipamento falhar. Porém, o sistema back up é utilizado de algumas formas diferentes: i) Back up idêntico com alternância de operação, onde o back up participa de um rodízio de operação com o equipamento principal; ii) Back up idêntico normalmente inativo, onde o back up passa por testes de verificação de execução de função, mas normalmente não entra em operação; iii) Back up diferente normalmente inativo, onde o back up passa por testes de verificação de execução de função, mas normalmente não entra em operação e possui características diferentes do equipamento principal; $i v$ ) Back up de carga compartilhada, onde se um equipamento do sistema redundante falhar, o outro tem sua carga compartilhada para evitar a perda da função. 
Para a manutenção destes sistemas redundantes são utilizadas estratégias de manutenção preditiva, preventiva e corretiva. A base para a definição dos intervalos de manutenção, tanto preditiva como preventiva, é os manuais dos fabricantes e a experiência da equipe de manutenção. Não são utilizados métodos quantitativos para a definição de intervalos de manutenção, nem são feitos cálculos para estimar a confiabilidade dos sistemas.

Ainda que as empresas possuam sistemas aparentemente confiáveis, seria importante mensurar o grau de confiabilidade real dos sistemas empregados, a fim de avaliar se os riscos envolvidos na operação de cada sistema são compatíveis com os riscos que a empresa está disposta a assumir. Observa-se que, apesar de se coletarem dados de falhas e de manutenções ocorridas nas empresas, as mesmas não dispõem de métodos efetivos para determinar quantitativamente a sua confiabilidade, limitando-se ao conhecimento empírico. De fato, esses métodos não são encontrados nem na literatura, tampouco na prática industrial.

O Quadro 1 apresenta um quadro comparativo de tipos de redundâncias, métodos de análise de confiabilidade/segurança e gestão da manutenção utilizados e recomendados para as três empresas avaliadas. 
Quadro 1 - Quadro comparativo de tipos de redundâncias, métodos de análise de confiabilidade/segurança e gestão da manutenção utilizados e recomendados

\begin{tabular}{|c|c|c|c|c|c|}
\hline Empresa & $\begin{array}{l}\text { Utilização de } \\
\text { sistemas } \\
\text { redundantes } \\
\end{array}$ & $\begin{array}{l}\text { Tipo de sistema } \\
\text { redundante }\end{array}$ & $\begin{array}{c}\text { Principal } \\
\text { estratégia de } \\
\text { manutenção }\end{array}$ & $\begin{array}{c}\text { Base para definição de intervalos } \\
\text { entre manutenções }\end{array}$ & Recomendações para melhoria da confiabilidade \\
\hline $\begin{array}{l}\text { Refinaria de } \\
\text { petróleo }\end{array}$ & Grande & $\begin{array}{l}\text { Back up idêntico com } \\
\text { alternância de operação }\end{array}$ & $\begin{array}{l}\text { Manutenção } \\
\text { preditiva baseada } \\
\text { na condição }\end{array}$ & $\begin{array}{c}\text { Manuais de fabricantes, experiência e } \\
\text { histórico das inspeções preditivas do } \\
\text { equipamento. As manutenções devem, } \\
\text { preferivelmente, coincidir com o } \\
\text { período em que o equipamento está } \\
\text { inativo }\end{array}$ & $\begin{array}{l}\text { Avaliar a confiabilidade quantitativamente, a fim de } \\
\text { levantar os riscos envolvidos }\end{array}$ \\
\hline \multirow{3}{*}{ Siderúrgica } & \multirow{3}{*}{ Pequena } & $\begin{array}{l}\text { Back up idêntico } \\
\text { normalmente inativo }\end{array}$ & \multirow{2}{*}{$\begin{array}{l}\text { Manutenção } \\
\text { preventiva baseada } \\
\text { no tempo }\end{array}$} & Manuais de fabricantes e experiência & $\begin{array}{c}\text { Aplicar alternância de operação. Determinar os } \\
\text { intervalos entre manutenções considerando dados } \\
\text { quantitativos. Avaliar a confiabilidade } \\
\text { quantitativamente, a fim de levantar os riscos } \\
\text { envolvidos }\end{array}$ \\
\hline & & $\begin{array}{l}\text { Back up diferente } \\
\text { normalmente inativo }\end{array}$ & & Manuais de fabricantes e experiência & $\begin{array}{c}\text { Determinar os intervalos entre manutenções } \\
\text { considerando dados quantitativos. Avaliar a } \\
\text { confiabilidade quantitativamente, a fim de levantar } \\
\text { os riscos envolvidos }\end{array}$ \\
\hline & & $\begin{array}{l}\text { Back up de carga } \\
\text { compartilhada }\end{array}$ & Rodar-até-a-falha & & $\begin{array}{l}\text { Avaliar a confiabilidade quantitativamente, a fim de } \\
\text { levantar os riscos envolvidos }\end{array}$ \\
\hline \multirow{2}{*}{$\begin{array}{l}\text { Empresa de } \\
\text { alimentos }\end{array}$} & \multirow{2}{*}{$\begin{array}{c}\text { Muito } \\
\text { pequena }\end{array}$} & $\begin{array}{l}\text { Back up idêntico } \\
\text { normalmente inativo }\end{array}$ & \multirow{2}{*}{$\begin{array}{l}\text { Manutenção } \\
\text { preventiva baseada } \\
\text { no tempo }\end{array}$} & Manuais de fabricantes e experiência & $\begin{array}{c}\text { Aplicar alternância de operação. Determinar os } \\
\text { intervalos entre manutenções considerando dados } \\
\text { quantitativos. Avaliar a confiabilidade } \\
\text { quantitativamente, a fim de levantar os riscos } \\
\text { envolvidos }\end{array}$ \\
\hline & & $\begin{array}{l}\text { Back up diferente } \\
\text { normalmente inativo }\end{array}$ & & Manuais de fabricantes e experiência & $\begin{array}{c}\text { Determinar os intervalos entre manutenções } \\
\text { considerando dados quantitativos. Avaliar a } \\
\text { confiabilidade quantitativamente, a fim de levantar } \\
\text { os riscos envolvidos }\end{array}$ \\
\hline
\end{tabular}

Fonte: Autoria própria (2012) 


\section{Conclusões}

O objetivo principal deste trabalho foi identificar os métodos de análise de confiabilidade segurança e gestão da manutenção, atualmente empregados nas empregas que utilizam sistemas redundantes.

Após uma revisão de literatura sobre os tipos de sistemas redundantes existentes, foram feitas entrevistas semiestruturadas em três empresas de grande porte situadas na região metropolitana de Porto Alegre: uma empresa refinaria de petróleo, uma empresa siderúrgica e uma empresa de alimentos a base de soja. As entrevistas abordaram questões referentes aos tipos de sistemas redundantes utilizados pela empresa, a manutenção empregada nesses sistemas (tipos, intervalos, métodos) e a existência de causas comuns de falhas que afetariam ambos os equipamentos do sistema redundante.

Quanto às causas comuns de falha de ambos os equipamentos do sistema redundante, as três empresas relataram suas possibilidades. Em casos mais graves, as falhas são evitadas utilizando sistemas redundantes com equipamentos diferentes, em outros, julga-se que a falha seja pouco provável ou não gere um dano catastrófico.

Como tipo de sistema redundante é utilizado o tipo back up, onde um segundo equipamento com a mesma função é mantido em paralelo, pronto para entrar em operação, caso o primeiro equipamento falhar. Porém, o sistema back up é utilizado de algumas formas diferentes: i) Back up idêntico com alternância de operação; ii) Back up idêntico normalmente inativo; iii) Back up diferente normalmente inativo; iv) Back up de carga compartilhada.

Para a manutenção desses sistemas redundantes é utilizado como base os manuais dos fabricantes e a experiência da equipe de manutenção. Não são utilizados métodos quantitativos para a definição de intervalos de manutenção, nem são feitos cálculos para estimar a confiabilidade dos sistemas.

Ainda que as empresas possuam sistemas aparentemente confiáveis, seria importante mensurar o grau de confiabilidade real dos sistemas empregados, a fim de avaliar se os riscos envolvidos na operação de cada sistema são compatíveis com os riscos que a empresa está disposta a assumir. Observa-se que, apesar de se coletarem dados de falhas e de manutenções ocorridas nas empresas, as mesmas não dispõem de métodos efetivos para determinar quantitativamente a sua confiabilidade. De fato, esses métodos não são encontrados nem na literatura, tampouco na prática industrial.

Por fim, vale ressaltar as delimitações deste estudo. Este trabalho limitou-se ao estudo de três empresas de grande porte do setor de petróleo, siderúrgico e de alimentos. Todas as empresas se caracterizam por apresentarem processos produtivos contínuos, em maior ou menor grau. Julga-se que empresas com este tipo de processo e que envolvem elevados riscos de segurança possuem 
instalações industriais com maior número de sistemas redundantes. Não foram entrevistadas empresas com outros tipos de processo de manufatura.

\title{
Agradecimentos
}

Agradecemos à Coordenação de Aperfeiçoamento de Pessoal de Nível Superior (CAPES) e ao Conselho Nacional de Pesquisa e Desenvolvimento (CNPq) pelo fornecimento de bolsa de pesquisa. Também agradecemos às empresas que permitiram a realização deste estudo colaborando com a disponibilização de informações.

\begin{abstract}
This paper aims to identify methods of reliability, safety, and maintenance management analysis currently employed in companies that use redundant systems. The qualitative research is based on information obtained from literature, along with information gathered in semi-structured individual interviews with maintenance managers of three big companies: one oil refinery, a steel company and a company producer of soy-based foods. After reviewing the benefits and possible deficiencies of the methods of reliability, safet, and maintenance management analysis employed by each type of redundant system, was developed, as a result, a comparative table of types of redundancy, methods of reliability, safety, and maintenance management analysis used and recommended. It was observed that, although companies have apparently reliable systems, no quantitative methods are used to define intervals or to estimate the real systems reliability. Even if the companies collect failures and maintenance occurred data, they have no effective methods to quantitatively determine its reliability.
\end{abstract}

Key-words: reliability centered maintenance, redundant systems, maintenance planning.

\section{Referências}

AZARON, A; PERKGOZ, C; KATAGIRI, H; KATO, K; SAKAWA, M. Multi-objective reliability optimization for dissimilar-unit cold-standby systems using a genetic algorithm. Computers \& Operations Research. v. 36, p. 1562$1571,2006$. crossref

BLOOM, N. B. Reliability Centered Maintenance: implementation made simple. New York, McGraw-Hill, 2006.

COURTOIS, P.-J; DELSARTE, P. On the optimal scheduling of periodic tests and maintenance for reliable redundant components. Reliability Engineering and System Safety. v. 91, p. 66-72, 2006. crossref

DHILLON, B. S; SUBRAMANIAN, P. Reliability analysis of triple modular computer systems with redundant voters and restricted maintenance. Journal of Quality in Maintenance Engineering. v. 7, n. 2, p. 151-164, 2001. cross ref

ELERATH, J. G; PECHT, M. A Highly Accurate Method for Assessing Reliability of Redundant Arrays of Inexpensive Disks (RAID). IEEE Transactions on Computers. v. 58, n. 3, p. 289-299, 2009. crossref

FOGLIATTO, F. S; RIBEIRO, J. L. D. Confiabilidade e Manutenção Industrial. São Paulo: Campus - Elsevier, 2009.

HSIEH, Y.-C. A linear approximation for redundant reliability problems with multiple component choices. Computers \& Industrial Engineering. v. 44, p. 91-103, 2002. crossref

LAFRAIA, J. R. B. Manual de confiabilidade, mantenabilidade e disponibilidade. Rio de Janeiro: Qualitymark, 2001. 
MÁRQUEZ, A. C; LÉON, P. M; FERNÁNDEZ, J. F. G; MÁRQUEZ, C. P; CAMPOS, M. L. The maintenance management framework. A pratical view to maintenance management. Journal of Quality in Maintenance Engineering, v. 15, n. 2, p. 167-178, 2009. crossref

MARSEGUERRA, M; ZIO, E; PODOFILLINI, L; COIT, W. Optimal Design of Reliable Network Systems in Presence of Uncertainty. IEEE Transactions on Reliability. v. 54, n. 2, p. 243-253, 2005. crossref

MYERS, A; RAUZY, A. Efficient Reliability Assessment of Redundant Systems Subject to Imperfect Fault Coverage using Binary Decision Diagrams. IEEE Transactions on Reliability. v. 57, n. 2, p. 336-348, 2008. crossref

NGUYEN, D. Q; BRAMMER, C; BAGAJEWICZ, M. New tool for the evaluation of the scheduling of preventive maintenance for chemical process plants. Industrial \& Engineering Chemistry Research, v. 47, n. 6, p. 110-124, 2008. cross ref

NIU, G; YANG, B; PECHT, M. Development of an optimized condition-based maintenance system by data fusion and reliability-centered maintenance. Reliability Engineering and System Safety. v. 95, p. 786-796, 2010. cross ref

PATÉ-CORNELL, M. E; DILLON, R. L; GUIKEMA, S. D. On the Limitations of Redundancies in the Improvement of System Reliability. Risk Analysis. v. 24, n. 6, p. 1423-1436, 2004. crossref

PINTO, A. K; XAVIER, J. A. N. Manutenção: função estratégica. 2. ed. Rio de Janeiro: Qualitymark, 2001.

RAUSAND, M. Reliability Centered Maintenance. Reliability Engineering and System Safety, v. 60, p. 121-132, 1998. cross ref

SANTOS, W. B; COLOSIMO, E. A; MOTTA, S. B. Tempo ótimo entre manutenções preventivas para sistemas sujeitos a mais de um tipo de evento aleatório. Revista Gestão e Produção, v. 14, n. 1, p. 193-202, 2007. cross ref

ZHANG, Y. L; WANG, G. J. A deteriorating cold standby repairable system with priority in use. European Journal of Operational Research. v. 183, p. 278-295, 2007. crossref

\section{Dados dos autores}

\section{Nome Completo: Angélica Alebrant Mendes}

Filiação Institucional: Universidade Federal do Rio Grande do Sul - UFRGS

Função ou cargo ocupado: Doutoranda do Programa de Pós-Graduação em Engenharia de Produção e Transportes.

Endereço completo para correspondência: Av. Osvaldo Aranha, 99, Porto Alegre, RS, CEP 90035-190

Brasil

Telefone: (51) 33083491.

e-mail: angelalebrant@yahoo.com.br

\section{Nome Completo: José Luís Duarte Ribeiro}

Filiação Institucional: Universidade Federal do Rio Grande do Sul - UFRGS

Função ou cargo ocupado: Professor do Departamento de Engenharia de Produção e Transportes..

Endereço completo para correspondência: Av. Osvaldo Aranha, 99, Porto Alegre, RS, CEP 90035-190

Brasil

Telefone: (51) 33083491.

e-mail: ribeiro@producao.ufrgs.br 
Submetido em:

Aceito em: 